\section{Arthritis Awareness Month - May 2016}

May is Arthritis Awareness Month. The 2016 theme for the observance is "See Arthritis" (http://www.cdc. gov/features/arthritisawareness/index.html). The theme is designed to raise awareness about the seriousness of arthritis by focusing on accounts from persons affected by the disease.

An estimated 52.5 million (22.7\%) adults in the United States have self-reported doctor-diagnosed arthritis. Of those, 22.7 million (9.8\% of U.S. adults) have arthritisattributable activity limitation (AAAL) (1). Arthritis also commonly co-occurs with obesity, heart disease, and diabetes (1). The prevalence of arthritis is projected to increase $49 \%$ to 78.4 million ( $25.9 \%$ of U.S. adults) by 2040 , and the number of adults with AAAL is projected to increase $52 \%$ to 34.6 million (11.4\% of U.S. adults) (2). Arthritis and AAAL will remain large and growing problems for clinical and public health systems for many years to come. Clinicians and public health professionals might find these projections useful in planning for future clinical and public health needs, including health care utilization, workforce demands, and health policy development.

Information about arthritis and proven communitybased programs that can help with managing arthritis is available at http://www.cdc.gov/arthritis and http://www. cdc.gov/arthritis/interventions.

\section{References}

1. CDC. Prevalence of doctor-diagnosed arthritis and arthritisattributable activity limitation-United States, 2010-2012. MMWR Morb Mortal Wkly Rep 2013;62:869-73.

2. Hootman JM, Helmick CG, Barbour KE, Theis KA, Boring MA. Updated projected prevalence of self-reported doctor-diagnosed arthritis and arthritis-attributable activity limitation among US adults, 2015-2040. Arthritis Rheumatol 2016. Epub March 25, 2016. http://dx.doi.org/10.1002/art.39692

\section{Prevalence of Doctor-Diagnosed Arthritis at State and County Levels - United States, 2014}

Kamil E. Barbour, $\mathrm{PhD}^{1}$; Charles G. Helmick, $\mathrm{MD}^{1}$; Michael Boring, $\mathrm{MS}^{1}$; Xingyou Zhang, $\mathrm{PhD}^{1}$; Hua Lu, $\mathrm{PhD}^{1}$; James B. Holt, $\mathrm{PhD}^{1}$

Doctor-diagnosed arthritis is a common chronic condition that affects approximately 52.5 million (22.7\%) adults in the United States and is a leading cause of disability $(1,2)$. The prevalence of doctor-diagnosed arthritis has been well documented at the national level (1), but little has been published at the state level and the county level, where interventions are carried out and can have their greatest effect. To estimate the prevalence of doctor-diagnosed arthritis among adults at the state and county levels, CDC analyzed data from the 2014 Behavioral Risk Factor Surveillance System (BRFSS). This report summarizes the results of that analysis, which found that, for all 50 states and the District of Columbia (DC) overall, the age-standardized median prevalence of doctor-diagnosed arthritis was $24 \%$ (range $=18.8 \%-35.5 \%$ ). The age-standardized model-predicted prevalence of doctordiagnosed arthritis varied substantially by county, with estimates ranging from $15.8 \%$ to $38.6 \%$. The high prevalence of arthritis in all counties, and the high frequency of arthritisattributable limitations (1) among adults with arthritis, suggests that states and counties might benefit from expanding

\author{
INSIDE \\ 495 Binational Dengue Outbreak Along the United \\ States-Mexico Border - Yuma County, Arizona, and \\ Sonora, Mexico, 2014 \\ 500 Announcements \\ 503 QuickStats
}

Continuing Education examination available at http://www.cdc.gov/mmwr/cme/conted_info.html\#weekly.

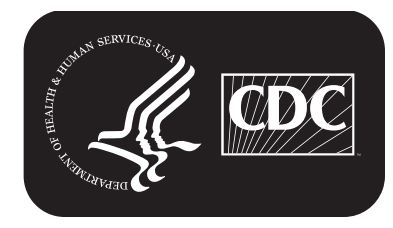

U.S. Department of Health and Human Services Centers for Disease Control and Prevention 